\title{
El discurso del periodismo deportivo: entre las filosofías de la vida y la guerra por otros medios
}

\author{
Carlos MANGONE
}

\section{INTRODUCCIÓN}

No es necesario comprobar las horas que los medios dedican al deporte para darse cuenta de la creciente importancia que las prácticas profesionales deportivas adquieren en la agenda cotidiana. Los comentarios en los lugares de trabajo y de estudio muestran claramente que la peripecia "deportivista" -en oposición a una caída popular de la práctica deportiva social- es seguida con la atención que anteriormente se le brindaba a otros temas.

Algunas cuestiones demográficas articulan la explosión mediática del deporte, especialmente el fútbol y el básket de la NBA. El crecimiento de la población impide la "experiencia directa" del espectáculo a millones de personas, además de los límites económicos y el apremio de la violencia del contorno deportivo que sucede en muchos paises. La superficialidad de los contactos comunicacionales cotidianos explica, en parte, la necesidad de nuevos actores sociales por involucrarse en "culturas deportivistas" que antes se rechazaban -como es el caso de la participación de mujeres- para mantener códigos de relación con la otra mitad (lo que modifica sustancialmente el diseño de la oferta industrial cultural de la mercancía "deportista profesional"). Este sobredimensionamiento espectacular -en el doble sentido del términode la difusión deportivista disimula bastante algunos componentes fundamentales del discurso del periodismo deportivo, que si bien mantienen una continuidad con la tradición, por el salto que implica la masividad y la globalización comunica- 
cional, adquieren características peculiares y preocupantes. Nuestro objetivo será repasar algunas de ellas como una introducción a un discurso que simula ser la "razón-pasión" de muchas existencias.

\section{LENGUAJE BÉLICO}

Desde siempre el deporte competitivo "expresó" de alguna forma una analogía con la guerra. Los Juegos Olímpicos resultaban una suerte de sublimación guerrera en tiempos de paz y el nacionalismo deportivo actual es uno de los últimos refugios del nacionalismo. Si bien el lenguaje de la crónica, del comentario y de la titulación del acontecimiento deportivo siempre estuvo encuadrado en estos términos, su metaforización no se veía rodeada de la agresividad que el entorno promueve. Las analogías épicas de relatores y cronistas juegan hoy el contrapunto con los cantos guerreros y desafiantes de las tribunas y de las "formaciones especiales" o "comandos urbanos irregulares" que parecen ser los más "pesados" de las hinchadas, sobre todo futbolísticas. En este contexto, la utilización de la metáfora bélica cobra otro sentido que, aunque no nos haría caer en teorias manipulatorias de la comunicación masiva, nos podrian hacer reflexionar sobre el hecho de que el campo fue modificado lo suficiente como para que un mismo discurso tenga otro efecto y quizás no de los más deseables.

\section{EL DISCURSO DEL DRAMATISMO}

Como una derivación del anterior, nos referimos a la hiperbolización no sólo de la importancia del deporte profesional mediático sino de las peripecias que lo rodean, una suerte de farandulización que necesita del catastrofismo para mantener la atención, ya no sólo a lo largo de noventa minutos sino de toda la semana. El vaivén de los resultados podría desalentar las expectativas, por lo que se necesita acentuar la importancia de la derrota y de la intriga palaciega. Este nuevo lugar de la derrota deportiva (minuciosidad del análisis de las causas y sobre todo indicación expresa de los responsables) nos informa acerca de un mercado deportivolaboral "apremiado" por un ejército de reserva cada vez mayor de jugadores, técnicos y dirigentes sociales y políticos que desean ocupar un número de puestos que es el mismo de los comienzos: en cantidad de clubes, jugadores por equipo y técnicos por cada división. Las llamadas corrientes "re- 
sultadistas" del deporte profesional son la coronación de toda esta tendencia dramática del discurso del periodismo deportivo que utiliza una serie de términos que, como veremos más adelante, pertenecen a una visión mítico-cíclica de la realidad. Todo lo que ocurre resulta "increíble", "lo más importante del siglo", hasta que ocurra nuevamente.

\section{EL SENTIDO COMÚN}

Aquí nos referimos a la divulgación de ciertos saberes que van preparando el terreno para el desarrollo de prejuicios y de ideologías de base del periodismo deportivo. La presencia de importantes cuotas de sentido común ayudan a percibir el campo lo suficientemente alejado de cualquier afán cientificista o seudofilosófico, como para que cualquier análisis cultural comience una tarea de jerarquización de las prácticas sociales. "Atacar o defenderse", "jugamos mejor con diez o nos perjudica", "ganar motiva o compromete", "la localía es una ventaja o una desventaja", "venir mal en el torneo nos quita presiones o nos angustia al punto de seguir jugando mal". Formaciones discursivas que colaboran para llenar horas de reflexiones que se van convirtiendo en una "rutina de flexiones diarias”, quizás las únicas que el público deportivista realiza como contrapunto del consumo mediático del deporte. No es casual, entonces, que el deporte mediático, sobre todo el futbolístico, sea un receptáculo pero a la vez una usina de refraneros que se sostienen semánticamente a partir del sentido común, como bien lo ejemplificaba Gramsci para dar cuenta de la influencia de la ideología de la clase dominante en las prácticas y discursos de los subordinados.

\section{LA MINUCIA DEPORTIVA}

La expansión mediática del deportivismo, a diferencia de otras coberturas (la del espectáculo artístico o la política), lleva al paroxismo la crónica de los acontecimientos, casi en tiempo real, en donde la enunciación y el enunciado se confunden en el trabajo de movileros, cronistas de prácticas y entrenamientos y en la descripción pormenorizada de los pasos de los deportistas durante toda la semana. Una suerte de inteligencia logística hace que periodistas deportivos se especialicen en clubes, algo tan impensable en otros tiempos de "imparcialidad" como imprescindible en estas épocas de necesidad de información permanente y, por lo tanto, de una confianza que sólo la da un trato cotidiano. Esta descripción 
cotidiana acentúa la despersonalización que supone seguir el recorrido, la tarea de "otro" (el sentido original de alienado). El discurso del periodismo deportivo actualmente se repliega de la cuantificación estadística y se especializa en la descripción cronológica de los campamentos de los guerreros y, como se advertirá enseguida, de las oscilaciones "financieras" de los protagonistas.

\section{FILOSOFÍAS DE VIDA}

Como una conclusión de la "caída de los grandes relatos" florecieron muchos microrrelatos, ideologias de base que explican los lugares en el mundo y en parte nos justifican. Si en otros tiempos la vida cotidiana y hasta la privada era leída desde esos grandes relatos (se era cristiano, liberal o marxista a grandes rasgos), actualmente la lectura del mundo arranca del prisma más acotado de identidades menos ambiciosas. Los "hobbies" se han transformado en ideologías. La militancia de la tribuna, la nueva fidelidad en la derrota, el "aguante" como se lo conoce en el Río de la Plata, resulta el espacio adecuado para que cierta sofisticación semióticocultural le dé un estatuto tal como para convertirlo en objeto de análisis. Ya se dijo, el fútbol cuando es transmitido por televisión o como tema de conversación no sólo establece el cronograma de las reuniones parlamentarias sino que parece ser la referencia de "filosofias de vida" que vuelven "defraudadas" de lo religioso, de lo social y de lo politico.

Mientras el análisis sociocultural busca causalidades de los comportamientos deportivistas que incluso llegan a construir fragmentos de una cultura internacional-popular, la vida real "comentada" se nutre de la discursividad deportiva. La política se deportiviza en la estructura de la competencia electoral en cuanto a las cifras y se vuelve publicitaria en los formatos y diseños. El resultadismo es la misma cara de la moral del éxito de los tiempos del neoliberalismo y la meta no es solamente un objetivo sino un arco en el campo de fútbol. Se dice en mi país "goles son amores y no buenas razones". El tiempo de los razonamientos es el de los comentarios de los periodistas deportivos.

\section{UNA VISIÓN MíTICO-CÍCLICA}

El discurso del periodismo deportivo cada vez más anclado en la experiencia popular del deporte mediático y cada vez más usina de la codificación lingüística que permite la vi- 
sibilidad de esa misma experiencia popular (las hinchadas cantan y hacen "bandera" para las cámaras) se basa en una serie de arquetipos que se vuelven estereotipos discursivos y que, como en la mitología, acentúan en forma desmesurada un rasgo, actitud o aptitud de los protagonistas. Desde los sobrenombres hasta la tipología caracterológica (que en la NBA sirve para los fines del marketing) implica que en el deporte, salvo excepciones que suelen definirse como reyes, dioses o magos (sean Pelé, Maradona o Jordan) siempre habrá un discurso para la garra, la inteligencia, la picardía, la velocidad, la fuerza, etc., virtudes que se cantan y se cuentan para una mejor comunicación de los mensajes. La visión mítica obviamente naturaliza todo y como la propia naturaleza repite aquello de "es increíble que se pierda un gol asî", "eso es imposible", para decirlo todos los domingos, aunque actualmente por la explosión "financiera" del deporte mediático se produce todos los dias.

\section{"NACIONALISMO" DE LA INDUSTRIA CULTURAL: EL CASO DEL PERIODISMO DEPORTIVO}

Como una suerte de consuelo de la desnacionalización económica de América Latina, de la privatización multinacional de sus empresas públicas y de la "neocolonización" de sus principales recursos, el discurso del periodismo deportivo mantiene "bien altas" las banderas de la diferenciación nacional para que se refuercen "aquellas identidades" actualmente agredidas por el proceso de globalización mundial. Lo que resultaria lógico en la estrategia mercantil-cultural norteamericana, europea o japonesa se convierte en una paradoja hipócrita en las empresas de comunicación latinoamericanas que en líneas generales apoyan el neoliberalismo "reinante". La picardía o el genio futbolístico maradoniano no "devuelve" las Malvinas, salvo en la "venganza" amarillista de los diarios y en el énfasis de la arenga guerrera de los micrófonos "combatientes". Sin embargo, la misma globalización entra en contradicción con estas intenciones seudonacionalistas de los medios y fundamentalmente del discurso del periodismo deportivo. El apogeo financiero en el deporte mediático debilita las lealtades nacionalistas de los "protagonistas", incluso a nivel de clubes, hasta tal punto que resulta difícil encontrar predominio "inglés" en el Manchester United o "turco" en el Galatassaray. En muchos casos el falso nacionalismo se vuelve un ex abrupto ético-periodístico: "Los paraguayos no sólo perdieron en fútbol: un acuchillado", titu- 
lar del diario Crónica de Buenos Aires, luego de un partido por las eliminatorias. Se puede mencionar también lo ocurrido con la palabra "macacos" utilizada por el diario deportivo Olé para referirse a los brasileños o la publicidad de Adidas en Brasil denominando "animales" a los zagueros argentinos.

Este último refugio discursivo del nacionalismo puede servir para los fines de la defensa "nacional" de los intereses patrios pero no puede disimular, como en el ejemplo de Bolivia, que la legítima reivindicación de elegir el sitio en donde disputar sus partidos de selección fuera reclamado por un Presidente de la República que modulaba la lengua castellana en forma muy parecida a sus "verdugos" de la FIFA.

\section{RACISMO}

Los nuevos condicionamientos mediáticos del deportivismo necesitan de un protagonista que se adapte a los formatos, sobre todo televisivo-publicitarios; que "circule" como moneda de una sola cara, un look inscrito en la tradición televisiva que muestra una pantalla más rubia que el continente y con una clase media urbana que conduce los programas, articula sus argumentos y expresa las opiniones más prestigiosas. Los talk shows quedan para el "exotismo" falsamente participativo de los sectores más subordinados. Los nuevos perfiles promueven un "carisma" (no como significado weberiano sino como significante un tanto posmoderno) que convierten al deportista en mercancía de múltiple rentabilidad, de ahí que la temprana esponsorización en sus años adolescentes o juveniles tenga en cuenta su disposición a participar de la narración televisiva, a modelar publicitariamente y a mostrar su vida cotidiana o privada. Esta parte de un racismo "concreto" (que se relaciona con un deporte superfísico que imposibilita la llegada "proteica" de los humildes y sumergidos del continente) está articulada con el racismo cotidiano del relato deportivo y de la tribuna. La ofensa al contrario (adversario o enemigo según los momentos de la batalla, protocolo de tribunas o cuerpo a cuerpo en la calle) pasa por los lugares comunes del reaccionarismo tradicional. La rivalidad se expresa en el agravio ("negro, puto" e incluso en algunos algunos adjetivos racistas o nacionalidades: "judío" o "boliviano", en realidad "bolita"). Lo que sería algo habitual de la pasión-sin razón de las multitudes se convierte en el peligroso ejercicio impune de la palabra mediática por parte de los periodistas deportivos. El relato televisivo hegemónico en la Argentina transita, lamentablemente (palabra 
olvidada en el análisis cultural) por esos senderos. No es infrecuente escuchar en alguna que otra transmisión radial algo así como: "Al lago Titicaca le cambias la gente y es Suiza", o apuntar ante un paneo de cámara en la tribuna: "iQué carita, eh!”, al mejor estilo lombrosiano de la criminología del siglo pasado.

La supuesta recuperación "afectiva" de todos estos términos no puede obviar el "efecto" permanente que produce sobre todo en épocas en que la crisis económica, la desocupación, la inmigración desesperada y la lucha por la sobrevivencia resulta, históricamente, el mejor marco para construir "diferentes culpables". Momento crucial en que el nacionalismo cambia una letra y la industria cultural se "asusta" y realiza informes especiales.

\section{LA DIMENSIÓN FINANCIERA: DISCURSO Y MERCANCÍA}

La proliferación de la palabra deportivista mediática es la expresión de la dominación financiera en el campo del deporte profesional de alta competencia, la contracara de la caída del deporte social, masivo, planificado y controlado científicamente. El abuso del "significante" y la poca preocupación axiológica por los significados se asimila a los escasos escrúpulos de la mayoría de los negocios financieros.

La generación de torneos, transferencias de deportistas, esponsorizaciones varias, contratos de publicidad, categorias cronológicas, etc., resultan movimientos adecuados a este final de siglo que tiene en cuenta más las demandas solventes (en este caso de un mercado de capitales) que las demandas sociales. No resulta casual, entonces, que navegue en los ámbitos que describimos la sospecha de ser el receptáculo de dineros negros que explicarían el crecimiento geométrico de los valores de las transferencias, la compra de derechos mediáticos o los contratos "inmoralmente" sobredimensionados de las principales figuras.

La preeminencia de lo financiero también modifica sustancialmente características declamadas no sólo del deporte competitivo sino también de la tradición periodística en general. La acumulación económico-financiera de los multimedias los convirtió en sostenedores del "negocio": compró derechos de los deportistas, auspicia clubes y torneos, etc. La crítica deportiva está atravesada por "intereses superiores" condicionando el juicio (la tan mentada objetividad) de la misma manera que sucede con el crítico cinematográfico que debe evaluar la película producida por el diario o la emisora en que trabaja. 
Como el circuito financiero, que de alguna forma autojustifica su existencia, en el periodismo deportivo la importancia de los acontecimientos se medirá en tanto coincida o no con los auspicios de la empresa mediática. Esta proliferación financiera, además, es el sustrato de la intriga semanal sobre jugadores, técnicos, dirigentes, pases, contratos, etc., temáticas privilegiadas en desmedro de las estrategias deportivas o la estética del espectáculo. En este sentido, los periodistas deportivos hegemónicos no son indiferentes al posicionamiento público-mercantil de los protagonistas ("la bolsa de cotizaciones diaria"), convirtiéndose en "operadores" no tan objetivos de los valores del mercado.

\section{A MANERA DE CONCLUSIÓN}

Si bien la actividad fisica, como expansión "ociosa" de las masas, fue reglada como deporte por las elites, las clases populares la tomaron como propia y resignificaron su función social. El siglo vio entonces que el deporte como espectáculo formaba parte de la industria cultural más participativa y de emulación más generalizada. Alli se podría explicar la construcción de identidades culturales que hacen más complejo el dominio de clase o la imposición de modelos culturales. Sin embargo, el fin de siglo nos sorprende con una actividad deportiva profesional, concentrada y articulada económicamente con los medios que la promocionan y valorizan. Esta situación se enmarca en un mercado mundial signado por políticas de exclusión social, económica y simbólica, lo que determina que el analista cultural o discursivo, en este caso, del discurso del periodismo deportivo, no debería perder de vista que si bien los mecanismos de construcción de sentido pueden responder a tradiciones conocidas, los efectos variarán de acuerdo con todo lo mencionado. La ausencia de valorización crítica y de una jerarquización de prácticas sociales ayuda a la legitimación neopopulista de estos tipos de discursos. 